
Kidney
Blood Pressure
Research

Kidney Blood Press Res 2015;40:215-222

DOI: 10.1159/000368497
Published online: May 04, 2015

(c) 2015 S. Karger AG, Basel

www.karger.com $/ \mathrm{kbr}$

Accepted: March 10, 2015

1423-0143/15/0403-0215\$39.50/0

This is an Open Access article licensed under the terms of the Creative Commons AttributionNonCommercial 3.0 Unported license (CC BY-NC) (www.karger.com/OA-license), applicable to the online version of the article only. Distribution permitted for non-commercial purposes only.

\title{
Renalase Protects the Cardiomyocytes of Sprague-Dawley Rats Against Ischemia and Reperfusion Injury by Reducing Myocardial Cell Necrosis and Apoptosis
}

\author{
Xiaogang Li Zijian Xie Minyuan Lin Ruixia Huang Zhongshu Liang \\ Wei Huang Weihong Jiang
}

Department of Cardiology, The Third Xiangya Hospital of Central South University, Changsha, Hunan, China

\section{Key Words}

Renalase - Ischemia and reperfusion injury - Lentivirus - RNA interference - Recombinant renalase protein

\begin{abstract}
Background/Aims: Renalase, a novel flavoprotein expressed in the kidney and heart, reduces renal tubular necrosis and apoptosis, which suggests that it might protect against necrosis and/or apoptosis in myocardial ischemia reperfusion injury (MIRI). The present study thus explored the effects of renalase on Sprague-Dawley (SD) rats subjected to MIRI. Methods: We used Lentivirus-mediated RNA interference (RNAi) to inhibit the renalase gene expression in the heart tissue via pericardial cavity injection. The MIRI animal modal was established by blocking the left anterior descending artery for 45 mins followed by $4 \mathrm{~h}$ of reperfusion. Real-time PCR and western blotting were used to detect renalase expression in the heart tissue. Double staining and TUNEL were used to detect the necrosis and apoptosis in the myocardial cells, respectively. Results: All rats subjected to MIRI exhibited lower levels of renalase in the heart tissue than did the sham-operated group $(P<0.05, n=6)$. The (RNAi) group rats exhibited lower renalase levels than did the controls and also exhibited more serious necrosis $(7.12 \pm 0.56 \%$ vs. $3.32 \pm 0.93 \%, \mathrm{P}<0.05, \mathrm{n}=6)$ and apoptosis $(151.8 \pm 8.2 \%$ vs. $66.8 \pm 6.5 \%, P<0.05, n=6)$; however, pretreatment with the recombinant renalase significantly reduced myocardial cell necrosis $(1.51 \pm 0.12 \%$ vs. $4.13 \pm 0.02 \%, \mathrm{P}<0.05, \mathrm{n}=6)$ and apoptosis $(21.3 \pm 5.0 \%$ vs. $52.6 \pm 10.4 \%, \mathrm{P}<0.05, \mathrm{n}=6)$ relative to the control rats. Conclusions: Exogenous recombinant renalase protein reduced myocardial cell necrosis and apoptosis. Recombinant renalase protein might be a new cardiovascular drug for ischemia/IR injury.
\end{abstract}




\section{Kidney \\ Blood Pressure Research}

Kidney Blood Press Res 2015;40:215-222

\begin{tabular}{l|l}
\hline DOI: $10.1159 / 000368497$ & (C) 2015 S. Karger AG, Basel
\end{tabular}

Published online: May 04, 2015

www.karger.com/kbr

\section{Introduction}

Ischemic heart diseases are a worldwide health problem, and acute myocardial infarction (AMI) is a particularly severe threat to human life. The optimal therapeutic strategy for AMI is to open the infarcted arteries, but this is a major problem for patients who are subjected to operations involving MIRIs. Unfortunately, there are no effective and proven therapies to prevent or treat MIRI prior to opening infarcted arteries [1-3].

In 2005 [4], researchers found that one gene, i.e., renalase, is robustly expressed in the kidney and heart. Renalase is known to effectively degrade circulating catecholamines and to play a vital role in human ischemia-related diseases [5-6]. Presently, increasing numbers of studies are reporting that renalase regulates blood pressure and cardiac function [710]. We have also previously confirmed that renalase is involved in the regulation of the blood pressure in spontaneously hypertensive rats [11]. Furthermore, we have previously investigated renalase gene polymorphisms in patients with coronary heart disease (CHD), and our results indicate that the renalase gene might be associated with CHD [12]. Other investigators [5] have examined isolated perfused mouse hearts and found that renalase deficiency exacerbates myocardial ischemic injury and that the administration of exogenous renalase reduces myocardial necrosis. Additionally, renalase protects against renal IR injury by reducing renal tubular necrosis, apoptosis, and inflammation [13]. Thus, we hypothesized that renalase plays a vital role in the hearts of SD rats and might be beneficial in terms of protecting cardiomyocytes against MIRI.

In this experiment, we sought to examine the following issues: (1) whether local renalase deficiency in the cardiac tissue would exacerbate MIRI; (2) the relationships between renalase expression in the cardiac tissue, the plasma levels of renalase, and myocardial cell necrosis and apoptosis; and (3) whether recombinant renalase protein directly protects the cardiomyocytes of SD rats against injury following MIRI.

\section{Materials and Methods}

Immunohistochemical detection of renalase expression in normal heart tissues

Paraffin-embedded heart tissues were prepared and made into paraffin sections ( $4 \mathrm{um}$ ). Anti-renalase monoclonal antibodies were used as primary antibodies (ProTech, America), and SABC testing kits (Vector, America) were used to detect the expression of renalase in the heart tissues. Each testing step was performed according to the guidelines provided in the testing manual.

Construction and validation of SD rats with low renalase gene expression in the heart tissues

We had designed and screened the lentivirus vector mediated RNA interference oligonucleotides ' $\mathrm{LV}$ RNLS-RNAi, The vector is GV118(10.3kb) and the sequence of oligonucleotide is U6-MCS-Ubi-EGFP. The screened LV-RNLS-RNAi oligonucleotide $\left(200 \mathrm{ul}\right.$ and $\left.2 \times 10^{9} \mathrm{TU} / \mathrm{ml}\right)$ was injected into the pericardial cavity to inhibit renalase gene expression in heart tissue.

\section{Experimental animal groups and MIRI operation procedures}

Thirty-six SD rats (male, 10 weeks, $280 \mathrm{~g}-320 \mathrm{~g}$ ) were randomly and averagely divided into 6 groups (the rats were fed a standard diet and acclimatized for 10 days before the operations). The animal protocol was reviewed and approved by the Ethical Committee of XiangYa School of Medicine, Central South University. The following 6 experimental groups were created: 1. a renalase low-expression group (LV-mediated RNA interference; RNAi group)' 2. a negative control (RNAi-NC group)` 3. an operative control (Normal group)` 4. a sham-operation group' 5 . a pretreatment with renalase recombinant protein group 'Protein group' and 6. a PBS pretreatment (Vehicle group). The RNAi group received injection of the screened oligonucleotide ( $200 \mathrm{ul}$ and $2 \times 10^{9} \mathrm{TU} / \mathrm{ml}$ ) into the pericardial cavity 10 days before the MIRI operation. The RNAi-NC group was injected with LV-NC-shRNA (i.e., the same dose). The Protein group received subcutaneous injections of recombinant renalase protein $(1.5 \mathrm{mg} / \mathrm{kg}) 10 \mathrm{~min}$ before the MIRI operation. The Vehicle group was 


\section{Kidney \\ Blood Pressure Research}

\section{Kidney Blood Press Res 2015;40:215-222}

\begin{tabular}{l|l}
\hline DOI: $10.1159 / 000368497$ & (C) 2015 S. Karger AG, Basel
\end{tabular}

Published online: May 04, 2015

www.karger.com/kbr

injected with the same volume of PBS. The method used to establish MIRI was as follows: the left anterior descending artery (LAD) was blocked for $45 \mathrm{~min}$; and reperfusion was allowed for $4 \mathrm{~h}$.

Detection of necrotic areas with double staining

After the MIRI operations, double staining (4\% Evans blue and 1\% triphenyltetrazolium chloride, TTC) was used to identify the ischemic areas (i.e., the areas at risk), the normal areas (blue), and the infarcted areas (pale) across the entire heart. The infarcted areas are expressed as percentages of the total at-risk areas.

Detection of apoptotic cells by TUNEL

Terminal deoxynucleotidyl transferase-mediated biotinylated UTP nick end labeling (TUNEL) assays were performed with an in situ cell death detection kit (TMR red, Roche, Swiss). Frozen cardiac sections (5um) were prepared after the MIRI operations, and the apoptosis testing kit was used to detect cardiomyocyte apoptosis.

Real-time PCR and western blot detection of renalase expression in the heart tissues after MIRI.

The primers used for the renalase gene were the following: F: 5'-AAGA AGCG CAAC ACAG AGT-3'R:5'TGTG ACTC CAAA TGGG ACGGT-3; and $\beta$-actin was used as the reference gene (primer: F:5'- CATC CTGC GTCT GGAC CTGG-3', R: 5'- TAAT GTCA CGCA CGAT TTCC-3'). The renalase gene was then replicated using the real-time PCR technique. Anti-renalase monoclonal antibodies were used as primary antibodies (ProTech, America), and HRP-labeled goat-anti-mouse IgG (CW-Biotech, China) antibodies were used as secondary antibodies, and western blotting was performed to detect the renalase protein expression in the heart tissues.

\section{Statistical analyses}

The data were analyzed with SPSS version 21.0 and are expressed throughout the text as the means \pm the SEMs. T tests were used to compare means between two groups, and one-way ANOVAs with S-N-K multiple comparison tests were used to compare multiple groups. In all cases, $\mathrm{P}<0.05$ was taken to indicate significance. All figures were made with Graphpad Prism version 6.01.

\section{Results}

Analyses of the general parameters

There were no significant differences in age or weight between the 6 groups. However, significant differences were observed in the SBPs and HRs of the RNAi and RNAi-NC groups. These results are shown in Table 1.

Table 1. Blood pressures and heart rates of the 6 groups pre- and post-operation. Note: $* \mathrm{P}<0.05$, RNAi group vs. RNAi-NC group

\begin{tabular}{lcccccc}
\hline & \multicolumn{3}{c}{ Pre-operation } & \multicolumn{3}{c}{ Post-operation } \\
\cline { 2 - 6 } & \multicolumn{1}{c}{ SBP(mmHg) DBP(mmHg) HR $(\mathrm{bpm})$} & \multicolumn{2}{c}{ SBP(mmHg) DBP(mmHg) HR (bpm) } \\
\hline RNAi & $143.6 \pm 19.5^{*}$ & $99.2 \pm 5.8$ & $418.0 \pm 28.7^{*}$ & $153.6 \pm 16.7$ & $100.7 \pm 11.6$ & $469.1 \pm 41.1$ \\
RNAi-NC & $137.3 \pm 8.3$ & $87.5 \pm 5.0$ & $359.1 \pm 33.2$ & $149.8 \pm 12.2$ & $94.1 \pm 9.5$ & $438.3 \pm 46.0$ \\
Normal & $129.8 \pm 15.4$ & $89.0 \pm 13.7$ & $346.3 \pm 44.6$ & $157.2 \pm 9.9$ & $96.1 \pm 13.7$ & $411.4 \pm 39.7$ \\
Sham & $130.9 \pm 4.9$ & $98.6 \pm 5.7$ & $337.6 \pm 39.0$ & $148.0 \pm 4.4$ & $105.2 \pm 5.0$ & $391.8 \pm 26.4$ \\
Protein & $131.1 \pm 24.5$ & $93.2 \pm 9.5$ & $376.1 \pm 27.3$ & $158.8 \pm 11.7$ & $102.4 \pm 12.3$ & $430.2 \pm 43.9$ \\
Vehicle & $131.4 \pm 16.1$ & $100.3 \pm 11.7$ & $354.9 \pm 43.3$ & $149.7 \pm 9.7$ & $101.6 \pm 11.5$ & $421.5 \pm 41.1$ \\
\hline Note: ${ }^{*} \mathrm{P}<0.05$, RNAi group vs. RNAi-NC group & & & \\
\hline
\end{tabular}




\section{Kidney Blood Pressure Research}

Fig. 1. Immunohistochemical detection of renalase expression in the heart tissues. A: The arrow shows renalase expression in the myocardial cells, (200x). B: Negative control (PBS).
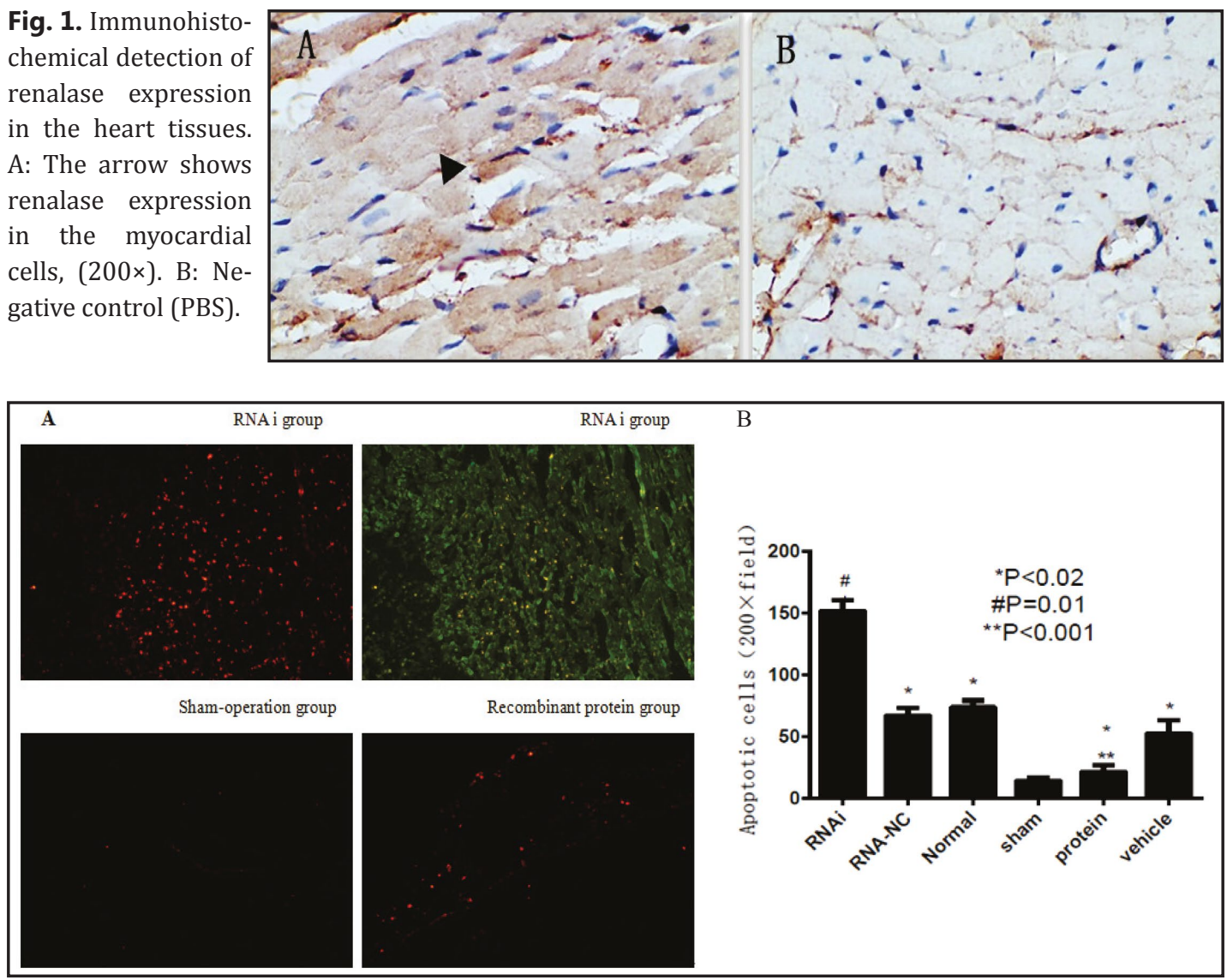

Fig. 2. A: TUNEL detection of the cardiomyocytes of the frozen cardiac sections $(100 \times)$. The tissue exhibited green coloring following the successful infection with LV-Rnls-RNAi. The apoptotic cells are show as red spots. B: Renalase deficiency accelerates cardiomyocyte apoptosis, and the recombinant protein reduces apoptosis during MIRI. ${ }^{*} \mathrm{P}<0.05$, versus the sham-operation group, $\mathrm{n}=6$; $\# \mathrm{P}<0.05$, RNAi group vs. RNAi-NC group, $\mathrm{n}=6$; ${ }^{* *} \mathrm{P}<0.05$, protein group vs. Vehicle group.

Renalase expression in the heart tissues of the normal SD rats

As shown in Figure 1.

Renalase-deficiency accelerated the cardiomyocyte apoptosis, and recombinant renalase protein reduced this process during MIRI

Figure 2 shows the results of the examinations of the frozen heart sections with the apoptosis kit. The apoptotic cells are shown as red spots. The tissues of the RNAi group were more prone to apoptosis following MIRI than were those of the control group (151.8 $\pm 8.2 \mathrm{vs}$. $66.8 \pm 6.5, \mathrm{P}<0.05, \mathrm{n}=6$ ), and treatment with recombinant renalase protein prior to the MIRI operations significantly ameliorated myocardial cell apoptosis (Protein group vs. Vehicle group, $21.3 \pm 5.0$ vs. $52.6 \pm 10.4, \mathrm{P}<0.05, \mathrm{n}=6$ ) (Figure2, B).

Double staining was used to separate the heart tissues into normal tissue, ischemia tissue, and infarcted tissue. The normal tissue stained blue, the ischemic tissue stained red, and the necrotic tissue failed to pick up the stain and appears pale. The same ischemic areas are present in different groups because the blocking positions were identical (Figure 3, the mean size was $28.2 \pm 0.32 \%$ ). However, the necrotic areas varied across groups. The RNAi group exhibited more necrotic area following MIRI than did the control group $(7.12 \pm 0.56 \%$ vs. 


\section{Kidney \\ Blood Pressure \\ Research}

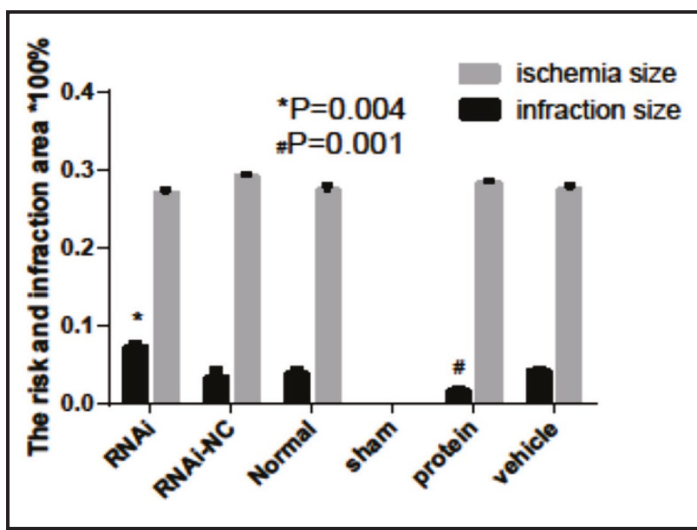

Fig. 3. The ischemic and infarcted areas of the different groups. ${ }^{*} \mathrm{P}<0.05$, RNAi group vs. RNAi-NC group, $\mathrm{n}=6$; recombinant protein reduced the necrotic area, $\# \mathrm{P}<0.05$, protein group vs. Vehicle group, $\mathrm{n}=6$.

$3.32 \pm 0.93 \%, P<0.05, \mathrm{n}=6$ ), and pretreatment with recombinant renalase protein prior to the MIRI operation significantly reduced myocardial cell necrosis (compared to the Vehicle group, $1.51 \pm 0.12 \%$ vs. $4.13 \pm 0.02 \%$, $\mathrm{P}<0.05, \mathrm{n}=6$ ).

The expressions of renalase $m R N A$ and protein in the cardiac tissue

The expression of renalase was obviously decreased following MIRI in all of the operation groups (with the exception of the sham-operation group; Figure 4).

\section{Discussion}

Myocardial cell necrosis, apoptosis, and local inflammatory reactions are the crucial pathological changes that occur during and after MIRI. Thus, the reduction of cell necrosis and apoptosis are thought to be effective clinical methods. Renalase was first identified in patients with end-stage renal disease and hypertension in 2005 [4]. Later, it was proven that renalase is expressed not only in the kidney but also in the heart, skeletal muscle, small intestine, brain, and peripheral nervous system $[14,15]$. Additionally, some researchers have reported the expression of renalase in the pancreas and in endothelial cells. An increasing number of reports are proving that renalase might be a new target for many diseases because it metabolizes circulating or local catecholamines [16-19].

Our immunohistochemical results revealed that most normal myocardial tissue expresses renalase. This finding indirectly indicates that renalase might play a vital role in local heart tissue. The low-expression renalase model was established with lentivirusmediated RNA interference technology. It can be inhibited more than $60 \%$ of renalase protein 


\section{Kidney Blood Pressure Research}

expression in SD rats [20-26]. We set the Left anterior descending coronary artery LAD) blocking time at $45 \mathrm{~min}$ and the reperfusion time at $4 \mathrm{~h}$ based on our previous preliminary experiment [27].

In our experiment, the interesting results revealed that decreased levels of renalase expression in the local tissue were associated with increases in necrotic area and apoptotic cell numbers; moreover, pretreatment with the recombinant renalase protein significantly ameliorated these injuries. Other researchers [13] have isolated mice hearts and exposed them to $15 \mathrm{~min}$ of global ischemia followed by reperfusion for $90 \mathrm{~min}$ and then assessed myocardial damage via triphenyltetrazolium staining of the heart. Similar to our findings, these findings of these experiments have indicated that renalase deficiency aggravates IR cardiac damage and that recombinant renalase reduces myocardial damage during IR. The same results were observed following the detection of myocardial cell apoptosis by TUNEL staining. Therefore, we propose that renalase plays a vital role in reducing cardiomyocyte necrosis and apoptosis during and after MIRI. However, one negative result from our experiment attracted our attention; the plasma renalase levels were not altered. Therefore, we considered that renalase might be not dependent of it's ability to metabolize catecholamines. Some researchers [28] had been reported that renalase protects renal proximal tubule cells against apoptosis in mice through the activation of Akt and p38-MAPK (mitogen-activated protein kinase) and the downregulation of c-Jun $\mathrm{N}$-terminal kinase, independent of amine oxidase activity. Therefore, we considered that the protective mechanism of renalase during the MIRI independent of amine oxidase activity and we will do further experiments to research the molecular mechanism. Ultimately, we believe that circulating renalase is primarily regulated by the kidney [29], but we have proven that renalase has different functions in different organs.

Our preliminary experiment had researched the plasma renalase mainly secreted by kidney and the serum creatinine, but during the process of MIRI, there were no significant difference either the circulating plasma renalase or the serum creatinine among the 6 groups. So we proposed that renal function just affects the plasma renalase level, there is other mechanism which regulates the metabolism of renalase independent on renal function in the local cardiac tissue. Whatever, kidney is the main organ which secrets the renalase, we also consider that renalase will be as a new brige between the regulation of cardiovascular diseases and renal function. In cardiac tissue, renalase is a crucial protein that regulates local cardiac function independent of amine oxidase activity. Exogenous recombinant renalase protein was able to produce robust protective effects against MIRI.

Thus, renalase might serve as a potential drug or a novel therapeutic target for the prevention and treatment of ischemic heart diseases. Specific molecular mechanisms of renalase other than the degradation of catecholamine might also exist, and further studies are needed to identify the mechanisms by which renalase protects cardiomyocytes against ischemia or ischemia-reperfusion injury.

\section{Conclusions}

Renalase deficiency in cardiac tissue exacerbated myocardial damage during and after the process of myocardial ischemia and reperfusion, and exogenous renalase protein protected against this damage by reducing cell necrosis and apoptosis. Recombinant renalase protein might have potential therapeutic value for MIRI and might be a novel cardiovascular drug for the treatment of IR injury.

\section{Disclosure Statement}

All the authors declare that they have no competing interests. 


\section{Kidney \\ Blood Pressure Research}

Kidney Blood Press Res 2015;40:215-222

\begin{tabular}{l|l}
\hline DOI: 10.1159/000368497 & (c) 2015 S. Karger AG, Basel
\end{tabular}

Published online: May 04, 2015

www.karger.com/kbr

$\mathrm{Li} /$ Xie/Lin/Huang/Liang/Huang/Jiang: Renalase in Myocardial Ischemia Reperfusion Injury

\section{Acknowledgments}

This study was supported by the Natural Science Foundation of Hunan Province (14JJ2035), Fundation for Key Disciplines of the Third Xiangya Hospital of Central South University and Special Funds for Fundamental Research in Central Universities (2013zzts344).

\section{References}

1 Bousselmi R, Lebbi MA, Ferjani M: Myocardial ischemic conditioning: Physiological aspects and clinical applications in cardiac surgery. J Saudi Heart Assoc 2014;26:93-100.

2 Gedik N, Thielmann M, Kottenberg E, Peters J, Jakob H, Heusch G, Kleinbongard P: No evidence for activated autophagy in left ventricular myocardium at early reperfusion with protection by remote ischemic preconditioning in patients undergoing coronary artery bypass grafting. PLoS One 2014;9:e96567.

3 Lloyd-Jones D, Adams RJ, Brown TM, Carnethon M, Dai S, De Simone G, Ferguson TB, Ford E, Furie K, Gillespie C, Go A, Greenlund K, Haase N, Hailpern S, Ho PM, Howard V, Kissela B, Kittner S, Lackland D, Lisabeth L, Marelli A, McDermott MM, Meigs J, Mozaffarian D, Mussolino M, Nichol G, Roger VL, Rosamond W, Sacco R, Sorlie P, Stafford R, Thom T, Wasserthiel-Smoller S, Wong ND, Wylie-Rosett J; American Heart Association Statistics Committee and Stroke Statistics Subcommittee: Executive summary: heart disease and stroke statistics--2010 update: a report from the American Heart Association. Circulation 2010;121:948-954.

4 Xu J, Li G, Wang P, Velazquez H, Yao X, Li Y, Wu Y, Peixoto A, Crowley S, Desir GV: Renalase is a novel, soluble monoamine oxidase that regulates cardiac function and blood pressure. J Clin Invest 2005;115:1275-1280.

5 Wu Y, Xu J, Velazquez H, Wang P, Li G, Liu D, Sampaio-Maia B, Quelhas-Santos J, Russell K, Russell R, Flavell RA, Pestana M, Giordano F, Desir GV: Renalase deficiency aggravates ischemic myocardial damage. Kidney Int 2011;79:853-860.

6 Li X, Huang R, Xie Z, Lin M, Liang Z, Yang Y, Jiang W: Renalase, a new secretory enzyme: Its role in hypertensive-ischemic cardiovascular diseases. Med Sci Monit 2014;20:688-692.

7 Fedchenko V, Globa A, Buneeva 0, Medvedev A: Renalase mRNA levels in the brain, heart, and kidneys of spontaneously hypertensive rats with moderate and high hypertension. Med Sci Monit Basic Res 2013;19:267-270.

8 Milani M, Ciriello F, Baroni S, Pandini V, Canevari G, Bolognesi M, Aliverti A: FAD-binding site and NADP reactivity in human renalase: a new enzyme involved in blood pressure regulation. J Mol Biol 2011;411:463-473.

9 Zbroch E, Koc-Zorawska E, Malyszko J, Malyszko J, Mysliwiec M: Circulating levels of renalase, norepinephrine, and dopamine in dialysis patients. Ren Fail 2013;35:673-679.

10 Desir GV, Tang L, Wang P, Li G, Sampaio-Maia B, Quelhas-Santos J, Pestana M, Velazquez H: Renalase lowers ambulatory blood pressure by metabolizing circulating adrenaline. J Am Heart Assoc 2012;1:e2634.

11 Guo Y, Li L, Tan L, Tang X, Yang Q, Jiang W: [Impact of renal denervation on expression of renalase and tyrosine hydroxylase in adult rats with spontaneous hypertension]. Zhong Nan Da Xue Xue Bao Yi Xue Ban 2012;37:829-833.

12 Li X, Jiang W, Li L, Huang R, Yang Q, Yang Y, Hong Y, Tang X: Renalase gene polymorphism in patients with hypertension and concomitant coronary heart disease. Kidney Blood Press Res 2014;39:9-16.

13 Lee HT, Kim JY, Kim M, Wang P, Tang L, Baroni S, D'Agati VD, Desir GV: Renalase protects against ischemic AKI. J Am Soc Nephrol 2013;24:445-455.

14 Hennebry SC, Eikelis N, Socratous F, Desir G, Lambert G, Schlaich M: Renalase, a novel soluble FADdependent protein, is synthesized in the brain and peripheral nerves. Mol Psychiatry 2010;15:234-236.

15 Wang J, Qi S, Cheng W, Li L, Wang F, Li YZ, Zhang SP: Identification, expression and tissue distribution of a renalase homologue from mouse. Mol Biol Rep 2008;35:613-620.

16 Desir GV, Peixoto AJ: Renalase in hypertension and kidney disease. Nephrol Dial Transplant 2014;29:22-28.

17 Koc-Zorawska E, Malyszko J, Malyszko JS, Mysliwiec M: VAP-1, a novel molecule linked to endothelial damage and kidney function in kidney allograft recipients. Kidney Blood Press Res 2012;36:242-247. 


\section{Kidney \\ Blood Pressure Research}

Kidney Blood Press Res 2015;40:215-222

\begin{tabular}{l|l}
\hline DOI: $10.1159 / 000368497$ & (C) 2015 S. Karger AG, Basel
\end{tabular}

Published online: May 04, 2015

www.karger.com/kbr

222 Injury

18 Zbroch E, Malyszko J, Malyszko J, Koc-Zorawska E, Mysliwiec M: Renalase, kidney function, and markers of endothelial dysfunction in renal transplant recipients. Pol Arch Med Wewn 2012;122:40-44.

19 Eikelis N, Hennebry SC, Lambert GW, Schlaich MP: Does renalase degrade catecholamines? Kidney Int 2011;79:1380-1381.

20 Reshi ML, Wu JL, Wang HV, Hong JR: RNA interference technology used for the study of aquatic virus infections. Fish Shellfish Immunol 2014;40:14-23.

21 Dong S, Cheng Y, Yang J, Li J, Liu X, Wang X, Wang D, Krall TJ, Delphin ES, Zhang C: MicroRNA expression signature and the role of microRNA-21 in the early phase of acute myocardial infarction. J Biol Chem 2009;284:29514-29525.

22 Dogini DB, Pascoal VD, Avansini SH, Vieira AS, Pereira TC, Lopes-Cendes I: The new world of RNAs. Genet Mol Biol 2014;37:S285-S293.

23 Dong Z, Wei F, Zhou C, Sumida T, Hamakawa H, Hu Y, Liu S: Silencing Id-1 inhibits lymphangiogenesis through down-regulation of VEGF-C in oral squamous cell carcinoma. Oral Oncol 2011;47:27-32.

24 Zhang S, Xiong K, Xie Z, Nan W, Liu H, Chen J: Stable silencing of beta-lactoglobulin (BLG) gene by lentivirus-mediated RNAi in goat fetal fibroblasts. Genet Mol Biol 2012;35:680-685.

25 Zhang YJ, Jia XH, Li JC, Xu YH: [Effect of HOXA10 gene silenced by shRNA on proliferation and apoptosis of U937cell line]. Zhongguo Dang Dai Er Ke Za Zhi 2012;14:785-791.

26 Li Y, Liang XY, Wei LN, Xiong YL, Yang X, Shi HG, Yang ZH: Study of RNA interference inhibiting rat ovarian androgen biosynthesis by depressing 17alpha-hydroxylase/17, 20-lyase activity in vivo. Reprod Biol Endocrinol 2009;7:73.

27 Meng XY, Yu HL, Zhang WC, Wang TH, Mai X, Liu HT, Xu RC: ZFP580, a novel zinc-finger transcription factor, is involved in cardioprotection of intermittent high-altitude hypoxia against myocardial ischemiareperfusion injury. PLoS One 2014;9:e94635.

28 Wang L, Velazquez H, Moeckel G, Chang J, Ham A, Lee HT, Safirstein R, Desir GV: Renalase prevents AKI independent of amine oxidase activity. J Am Soc Nephrol 2014;25:1226-1235.

29 Wang F, Xing T, Li J, Bai M, Hu R, Zhao Z, Tian S, Zhang Z, Wang N: Renalase's expression and distribution in renal tissue and cells. PLoS One 2012;7:e46442. 